\title{
Maximising seed production potential in white clover: factors influencing seed set per floret
}

\author{
R.G. THOMAS \\ Dept. of Plant Biology and Biotechnology, Massey University, Palmerston North
}

\begin{abstract}
The causes of low seed set per floret in white clover (Trifolium repens L.) are reviewed. Three stages of flower head development are distinguished as important for a high level of seed set: a pre-fertilisation stage, a stage of anthesis leading to pollination, and a postfertilisation stage in which seed provisioning occurs. In sunny conditions the percentage seed set is limited at the pre-fertilisation stage by up to $20-30 \%$ ovule sterility. Relatively low light intensities during the postfertilisation stage can lead to abortion of a high proportion of fertilised ovules and developing seeds. Experimental results suggest that seed yields under optimal growing conditions can be limited solely by the level of pre-fertilisation ovule sterility and probably cannot be bettered, but further understanding of the seed-provisioning requirements for photosynthate could lead to improved management practices for seed production under conditions of lower light intensities.
\end{abstract}

Keywords: abortion, light intensity, ovule, seed provisioning, sterility, white clover

\section{Introduction}

The most important underlying factor affecting seed production potential in white clover is flower head density, expressed as number of heads per metre ${ }^{2}$. Given this prerequisite, pollination becomes a major limiting factor. Management practices aimed at maximising seed production potential have been developed primarily with these two parameters in mind (e.g. Clifford 1980). In seed crops with high head density, though, and even under optimal conditions for pollination, theoretical maximum levels of seed production are never achieved. Although each ovary usually contains at least five ovules, the mean number of seeds produced per floret is rarely more than three or four and very commonly less than this (Thomas 1987). There is thus apparent potential for increasing seed yields per flower head by $20 \%$ to $50 \%$.

\section{Discussion}

The present paper discusses the scope which exists for increasing the level of seed production per flower head.
To date, some emphasis has been placed on observations which suggest that there might be competition for nutrient between developing seed heads and between developing seeds within pods and seed heads (e.g. Binek 1983; Clifford 1986; Khrbeet et al. 1993). To comprehend the factors limiting seed set, however, it is necessary to consider the full sequence of events leading from flower formation to seed maturation. In particular, it is important to distinguish three equally significant stages during this sequence, namely:

(a) a pre-fertilisation stage in which ovule number per floret and degree of ovule fertility are very important parameters,

(b) pollination and fertilisation, and

(c) a post-fertilisation stage during which there is abortion of some developing seeds.

\section{The pre-fertilisation stage}

(i) Ovule number per floret.

The number of ovules per carpel is determined at a very early stage of floret development (Thomas 1987). In every case reported, ovule number is highest in the lower, first-formed, florets on a flower head and least in the upper, later-formed, florets. In cv. Grasslands Huia studied by Thomas and Pasumarty (1996, in preparation), for instance, the ovule number per floret was found to range from 5.46 in the lowermost florets to 4.73-4.91 in the uppermost, resulting in a mean number per floret of approximately 5.10 .

\section{(ii) Ovule fertility}

The proportion of fertile ovules formed in white clover florets is surprisingly low. Studies of embryo sac development have shown clearly that ovule fertility is very sensitive to light intensity (Thomas \& Pasumarty, in preparation). At the very lowest intensities tested, close to the light compensation point for photosynthesis, ovules can be almost totally sterile and even under the brightest field conditions in open canopies the level of fertility in Grasslands Huia has been found to reach only about $70-80 \%$. Low light intensities act both directly on young developing inflorescences growing within dense foliage canopies, possibly by influencing the ratio of red-absorbing to far-red-absorbing phytochrome in them, and indirectly by lowering the level of available photosynthate. 
The above results lead to the hypothesis that ovule sterility might be primarily the result of nutrient shortage, lower light intensities decreasing fertility by lowering the supply of photosynthate. The observation that percentage fertility of ovules in upper florets is slightly less $(65 \%)$ than that of ovules in lower florets $(72 \%)$ supports this suggestion, the lower florets being closer to the peduncles which supply nutrient to the developing heads. Closer analysis, however, indicates that this suggestion is incorrect.

Two sets of observations suggest that ovule sterility is probably not attributable to nutrient shortage. The first is that the distribution of sterile ovules within ovaries is random. Were nutrient supply a limiting factor for the development of ovule fertility, it would be expected that ovules nearer the source of nutrient supply at the basal ends of florets would tend to be more fertile than those at the stylar ends. This is not so.

A second, and possibly more significant, set of observations was obtained from a field experiment with Grasslands Pitau white clover (Pasumarty \& Thomas 1990). In this experiment, plants shaded to a level of $45 \%$ during the pre-fertilisation stage were compared with others which remained fully exposed to natural light. Both groups received full natural light during the days following pollination. Pre-fertilisation shade reduced the number of seeds per pod in the lower florets to 3.20 from 3.74 in full light, and in the upper florets to 2.36 from 2.67 in full light. Pre-fertilisation shade thus reduced seed numbers in lower florets by $14.4 \%$ and in upper florets by $11.6 \%$. This strongly suggests that the difference in level of sterility of ovules between lower and upper florets was not the result of differential nutrient supply. Had the number of seeds per pod been affected by this means, seed number in upper florets would have been expected to be much more strongly affected than in the lower florets.

Different ovule numbers per ovary and different levels of fertility in lower and upper florets on one inflorescence should thus be considered attributable to inherent genetically regulated patterns of development rather than to competition between developing ovules. Overall availability of photosynthate to inflorescences appears to have a similar effect on florets at all positions along the length of an inflorescence.

Ovule sterility sets the upper limit on potential seed formation per floret. Using the examples cited above, theoretical potential seed numbers per floret can be calculated by multiplying:

(ovule number per floret $) \times($ percent ovule fertility $)$

In the lowermost florets of cv. Grasslands Huia with 5.46 ovules per floret and $72 \%$ ovule fertility, the calculated potential seed number per floret would be 3.96. In upper florets, with a mean ovule number per floret of 4.82 and $65 \%$ fertility, the potential seed number per floret would be 3.12 . These figures are remarkably similar to the highest average seed number per floret of 3.91 recorded for Grasslands Huia by Clifford (1986) and suggest that ovule sterility might be the major factor determining number of seeds per floret under optimal management regimes.

\section{The pollination stage}

As a factor influencing seed set, pollination by bees is obviously essential in the field, but a lack of pollination is demonstrably not the cause of the sub-optimal seed set per floret which is invariably observed under conditions of good pollination. Figure 1 compares the frequency of occurrence of carpels (seed pods) containing various numbers of seeds (ranging from 0 to 6 ) with the frequency of florets with various numbers of fertile ovules per carpel. Ovule fertility was determined on pre-fertilisation samples from unshaded flower heads of field-grown Huia plants which were later used for the determination of seed number per floret. Upper and lower florets were sampled separately.

The data in Figure 1 demonstrate the existence of an almost perfect correlation between the number of seeds produced per floret and the number of fertile ovules per carpel. Under the conditions of this experiment it is clear (a) that pollination must have in no way limited seed set, and (b) that the only underlying factor determining the number of seeds formed per floret was the number of fertile ovules present. Every fertile ovule developed into a seed. Thus the only way of increasing seed set per flower head above the maximum attainable using the best seed production management practices developed by Clifford would be to increase ovule fertility. As an inherent minimum level of up to $30 \%$ ovule sterility seems to be determined by the genetic constitution of white clover plants, improved seed production capacity with regard to this parameter requires genetic manipulation and seems unlikely to be attainable by improved management practice.

\section{The post-fertilisation stage}

The experiments described above demonstrate clearly that, under optimal conditions for pollination and growth, seed set per floret can be solely determined by the level of ovule fertility and that under such circumstances no, or very little, post-fertilisation seed abortion occurs. There can be no doubt, however, that under some conditions developing seeds do abort in the first few days after fertilisation. This has been shown incontrovertibly both by the present author and by Robbie (1989). It should be noted, though, that in 
Figure 1: Frequency distributions of the number of fertile ovules per carpel at the pre-fertilisation stage $(\mathbb{0})$ and the number of seeds formed per carpel after pollination (A). The upper graph (A) shows data from a sample of 300 upper florets and the lower graph (B) shows data from 300 lower florets sampled from the same flower heads.

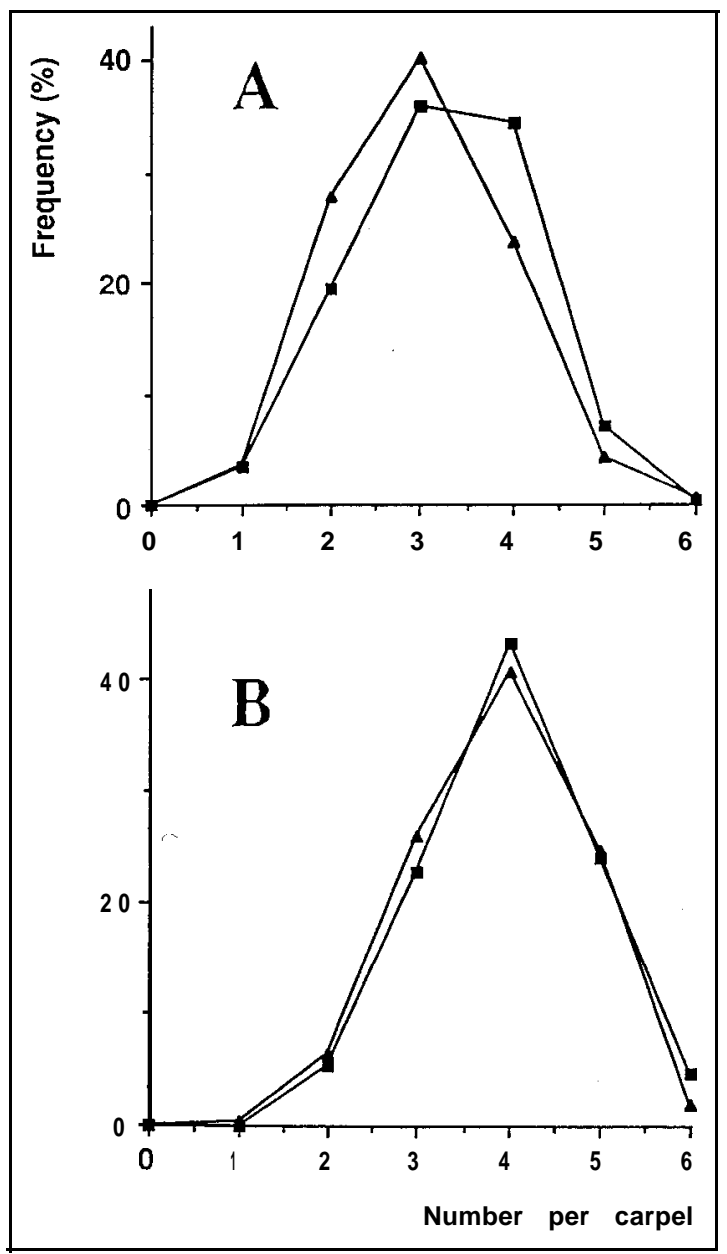

some published discussions of the problem of reduced seed set, including those by Clifford (1986), Robbie (1989) and Khrbeet et al. (1993), authors have been unaware of the existence of pre-fertilisation ovule sterility and have incorrectly attributed reduced seed set to post-fertilisation abortion only.

The degree of post-fertilisation abortion differs in different situations, ranging from almost nil in the cases described earlier to quite high levels in some instances. The present author, for instance, found as much as $25 \%$ post-fertilisation ovule abortion in wild S.184 clover growing in the United Kingdom compared with only
$4 \%$ in Grasslands Huia and $12 \%$ in Grasslands Tahora growing in New Zealand.

The cause of these differences in degree of postfertilisation abortion may well be related to the level of photosynthate available. Clifford (1986) ascribed the detrimental effects of water stress on 'seed provisioning' to the indirect effect of stress on photosynthetic ability. Subsequently it was shown by Pasumarty and Thomas (1990) that artificial post-fertilisation reduction of light intensity in the field reduced the mean number of seeds formed per floret by about $17 \%$, from 3.21 in full light to 2.66 in $45 \%$ light. Again, these authors assumed the reduction in light intensity to act directly on seed provisioning by reducing the rate of photosynthesis.

The notion that seed provisioning is dependent on photosynthate availability has led to suggestions, firstly, that the maximum attainable seed yield per plant is determined by the level of photosynthate available and secondly that, partly as a consequence, developing seeds compete with each other for photosynthate.

The first of these suggestions is supported by the observation that there seems to be a 'trade-off' between the number of seeds formed and the 1000-seed weight in some instances. This suggestion merits much fuller investigation. The second suggestion concerns competition between ovules within florets, between florets on the same flower head, and between flower-heads, but again is not fully supported by existing evidence.

Within florets, there is a slightly greater tendency for fertilised ovules nearer the style to abort than for those nearer the base of the floret which is nearer the source of nutrient supply (Thomas, unpublished). This supports the suggestion that ovules compete for nutrient during their early post-fertilisation phase.

Within flower heads there is invariably a difference between the upper and lower florets in both the number of ovules forming seeds and the percentage of ovules forming seeds. This difference should not be attributed solely to differential abortion of developing seeds, though. In some instances, at least, the difference clearly results from a greater degree of pre-fertilisation ovule sterility in the upper florets than the lower. And, significantly, Pasumarty and Thomas (1990) found that shading plants only during the post-fertilisation stage decreased the number of seeds by an equal amount (viz 15-18\%) in upper and lower florets. Had there been competition for photosynthate between upper and lower florets, the latter should have been favoured when the supply of photosynthate was limited. This result therefore suggests that, as with pre-fertilisation sterility, the differences between upper and lower florets are not primarily the result of competition between them.

In a different set of experiments, though, Khrbeet et al. (1993) found that reducing the number of florets 
per flower head from 40 to 20 did lead to an apparent increase in number of mature seeds formed per floret from 2.8 to 3.1 in one instance and from 2.3 to 3.4 in another. This result does certainly support the suggestion that nutrient availability can limit the number of seeds set per floret, although it does not necessarily imply that there is competition between the florets.

Two sets of observations can be interpreted as supporting the suggestion that whole flower heads compete with one another for photosynthates. Binek (1983) described experiments in which reduction of the number of flower heads per plant to 40 or 20 increased the number of seeds per head by 58 and $69 \%$ respectively. And when Khrbeet et al. (1993) removed flower heads from white clover seedlings to leave one, four or eight per plant they found the number of mature seeds formed per inflorescence to be 112.4, 91.1 and 86.4 respectively. In both these cases seed number per head was lower when number of flower heads was higher, but it is by no means certain that this result is necessarily the result of competition between heads.

\section{Conclusions}

In conclusion, it is important to understand the different outcomes to be expected in different environmental conditions. Post-fertilisation seed provisioning can be expected to be maximal when the incoming radiation levels are highest; that is in midsummer, when the sun is at its brightest and the days are longest. Trapping of this light per unit area of land will be maximal with high leaf area indices. The evidence suggests that in New Zealand under these conditions light intensities are sometimes not limiting seed provisioning and very little post-fertilisation ovule abortion occurs. All the clear cases of post-fertilisation abortion reported in this paper have occurred at lower irradiance levels or with other factors such as water stress possibly restricting photosynthesis. The observations of high levels of post-fertilisation abortion by Robbie (1989) and Thomas were made in the United Kingdom where highest light intensities are significantly lower than in New Zealand. The plants grown by Khrbeet et al. (1993) are described as having received levels of irradiance ranging from 350 to $820 \mu \mathrm{mol} . \mathrm{m}^{-2} \cdot \mathrm{s}^{-1}$ compared with maximum summer levels of over $2000 \mu \mathrm{mol} . \mathrm{m}^{-2} \cdot \mathrm{s}^{-1}$ received by field-grown plants in New Zealand.

Under conditions of sub-optimal light intensity, flower heads certainly compete with vegetative organs for photosynthate. Kawanabe et al. (1963) found flower head removal led to an increase in root and stolon dry weight compared with intact control plants; and Harvey (1970) found flower heads to act as strong competitive sinks during the seed-filling stage.
These observations point to a great need for a much sounder fundamental understanding of the relationship between post-fertilisation seed development, flower head size, flower head density, irradiance levels and the structure of the foliage canopy as a basis for developing optimal seed production management practices for use under sub-optimal growing conditions. There is also a need to clarify the role of mineral nutrients such as sulphur, boron and molybdenum as factors limiting seed set (Clifford \& White 1986) and to explore the possibility of increasing seed production potential by breeding for decreased ovule sterility.

\section{References}

Binek, A. 1983. The structure of seed yield in clones of white clover (Trifolium repens L.) after the reduction of inflorescences to a standard number per plant. Acta agraria et silvestria, Agraria 22: 21-29.

Clifford, P.T.P. 1980. Research in white clover seed production. In: Lancashire, J.A. (ed.). Herbage Seed Production. New Zealand Grassland Association Grassland Research and Practice Series No. 1: 6467.

Clifford, P.T.P. 1986. Interaction between leaf and seed production in white clover (Trifolium repens L.). Journal of Applied Seed Production 4: 37-43.

Clifford, P.T.P.; White, S.D. 1986. A sulphur response: white clover seed production. New Zealand Journal of Experimental Agriculture 14: 97-99.

Harvey, H.J. 1970. Patterns of assimilate translocation in Trifolium repens. Occasional Symposium of the British Grassland Society No. 6: 181-186.

Kawanabe, S.; Yoshihara, K.; Okada, T.; Ueno, M.; Hidaka, M. 1963. Studies on summer depression of pasture crops 3. Influence of flower bud removal upon vegetative growth of Ladino clover. Journal of the Japanese Society for Grassland Science 9: 34-41.

Khrbeet, H.K.; Marshall, A.H.; Hides, D.H. 1993. Effect of inflorescence and floret number on floret site utilisation of white clover. Journal of Applied Seed Production 11: 80-86.

Pasumarty, S.V.; Thomas, R.G. 1990. Effect of canopy structure and light intensity on seed production in white clover. Proceedings of New Zealand Grassland Association 52: 107-110.

Robbie, A. 1989. Seed development in white clover. p. 25. In: Report of the Welsh Plant Breeding Station for 1988 .

Thomas, R.G. 1987. Reproductive development. pp. 63-123. In: Baker, M.J.; Williams, W.M. (eds). White Clover. CAB International, Wallingford, U.K. 